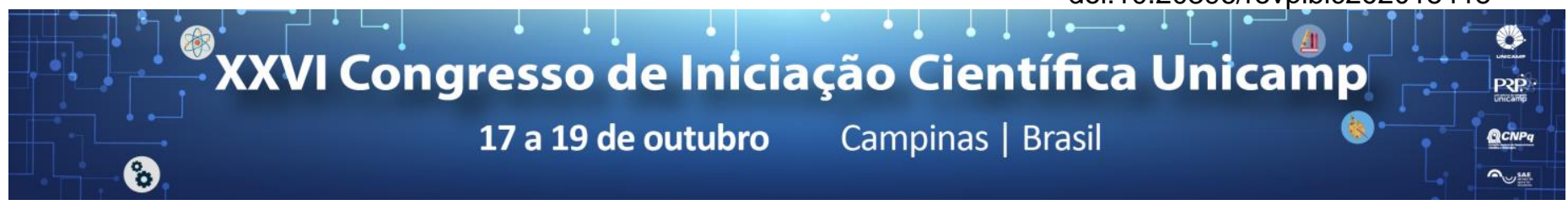

\title{
Development of Smart grid applications for Smart homes with Internet of Things.
}

\author{
Felipe Muhamed Avila*, L.F Avila
}

\begin{abstract}
This work aims at the study and construction of a system that unifies SmartGrid technologies with the Internet concepts of Things. The union of these creates a new concept called the Internet of Energy. The use of the Internet of things in this branch is precisely to promote an autonomous communication between the various intelligent objects through the internet, providing a greater intercommunication of the system. The application has as main goal to be applied in smart homes. It will be used to increase the efficiency of the home's electrical grid by providing power information currently spent by the connected devices to the user, giving greater control over energy expenditure and decreasing the amount paid by the homeowner in the energy bills at the end of the year. month. This information will all be provided through the Internet, thereby building an intelligent control system that can communicate with a user via the Web.
\end{abstract}

\section{Key words:}

Internet of Things, Smart Grids, Internet of Energy.

\section{Introduction}

Today, the Internet of Things has been taking on a large proportion of convergent technologies. the great appeal for sustainability that the Internet of Things offers has aroused great interest among many researchers and scientists seeking to develop technologies that bring greater social and technological growth. In addition to the Internet of Things, another very well-known concept in technology is smart grids, which bring an appeal to make inefficient old electrical networks into optimized smart grids that offer several benefits to society, such as greater energy savings. The work developed in this project consists of an application that seeks to increase efficiency in the energy expenditure of a home's electrical grid, providing information about the power expended at the moment of the connected equipment, giving the user greater control over energy expenditure and decreasing energy consumption. All of this information will all be provided through the Internet, with the help of an intelligent control system that can communicate with the user through the Web [1].

\section{Results and Discussion}

As a result, the intelligent energy management application built in this work consists of a well-structured hierarchy of operation, which starts from the obtaining of electrical data of a household equipment through the smart grid until the transmission of this data to the user through the internet using the Internet of Things [2].

With all the development of the system, after the construction of the entire sensor network connected to the microcontroller, the user application was developed with the role of bringing the electrical system data obtained by the sensors in an interactive way and easy reading for the user. The system also provided the user with control over the equipment connected to the application. The image 1 shows the data graph application screen.

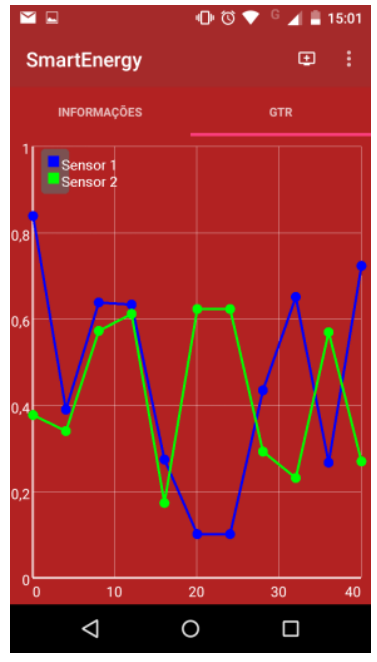

Image 1. Data graph of the application.

\section{Conclusions}

It is possible to see with this work that the motivational appeal that the combination of Internet of Things with Smart Grids is gigantic, bringing diverse gains to a society, for example, the awareness in the energetic consumption, the reduction in the excessive expenditures of electrical energy and economic education in a matter of consumption. Throughout all development, even with the difficulties of building the application, it was possible to verify its great applicability to the daily life of a society that seeks a beneficial technological growth and also that seek an improvement in its sustainability.

\section{Acknowledgement}

We thank the support of master degree student Thallyson Paulino da Silva Melo and PIBIC / CNPq / Funttel for financial support.

1 Dr. Ovidiu Vermesan, "Internet of Things: Converging Technologies for Smart Environments and Integrated Ecosystems", River Publishers, 2013

A. Jung, "Building the Internet of Energy Supply," Spiegel Online International,Dec. 2010 